\title{
HUBUNGAN SENAM OSTEOPOROSIS DENGAN KEJADIAN OSTEOPOROSIS PADA PESERTA SENAM DI RUMAH SAKIT ISLAM SURABAYA
}

\author{
Farida Umamah, Faisal Rahman \\ Fakultas Keperawatan dan Kebidanan \\ Universitas Nahdlatul Ulama Surabaya Jl. Smea 57 Surabaya \\ Email : umamahfarida@unusa.ac.id
}

\begin{abstract}
Gymnastic is important for health. In fact many people who do not do gymnastic for a variety of the reasons. Therefore, the purpose of this study was to find out the relationship between the gymnastic osteoporosis and osteoporosis and osteoporosis in the Surabaya Islamic General Hospital.The design of study was analytic correlational - crosss sectional. The population involved all participant of gymnastic osteoporosis in the Surabaya Islamic General Hospital, totally 55 people, 48 respondents were chosen as the samples by using simple random sampling technique. The independent variabel used in this study was gymnastic osteoporosis and the dependent variabel was the osteoporosis. Questionnaire and bone mass density was used to collect the data which were then analyzed by using Rank Spearman test with the significance level $\alpha=0,05$.The resulf of study showed that among 48 respondents almost antirely respondents were $(79,2 \%)$ Follow exercise according the rules, and most of the respondents $(68,8 \%)$ osteopenia. Moreover, the result of the statistics test showed that $\rho=0,00<\alpha=0,05$. So that $\mathrm{H}_{0}$ was rejected which meant that there was a coralation between gymnastic osteoporosis and osteoporosis in the Surabaya Islamic General Hospital.The conclusion is gymnastic beneficial to bone and other health aspec. Gymnastic can be slow the drop of bone mass dencity due to age and increase the general healt, so that decrease osteoporosis.
\end{abstract}

\footnotetext{
Abstrak : Senam osteoporosis penting untuk kesehatan, orang yang tidak mengikuti senam, menderita nyeri persendian, muda lelah, kram dimalam hari. Tujuan penelitian ini adalah untuk mengetahui hubungan senam osteoporosis dengan kejadian osteoporosis di Rumah Sakit Islam Surabaya. Desain penelitian ini menggunakan analitik observasional dengan pendekatan cross sectional. Populasi penelitian adalah peserta senam osteoporosis di Rumah Sakit Islam Surabaya sebesar 55 orang. Sampel sebesar 48 responden diambil dengan simple random sampling. Variabel independen senam osteoporosis, variabel dependen osteoporosis, pengumpulan data menggunakan kuesioner, alat ukur kepadatan tulang (DMT), data primer di analisis menggunakan uji statistk Rank Spearman dengan $\alpha=0,05$. Hasil penelitian menunjukkan dari 48 responden senam osteoporosis, hampir seluruhnya $(79,2 \%)$ mengikuti senam sesuai kaidah, sebagian besar $(68,8 \%)$ responden menderita osteopenia. Hasil uji Statistik Rank Spearman di dapatkan $\rho=0.001<\alpha=$ 0.05 sehingga $\mathrm{H}_{\mathrm{o}}$ ditolak, artinya ada hubungan antara senam osteoporosis dengan kejadian osteoporosis pada peserta senam osteoporosis di Rumah Sakit Islam Surabaya. Simpulan penelitian adalah senam osteoporosis yang sesuai 1 kali dalam seminggu minimal 40 menit sekali senam, dapat memperlambat penurunan massa
} 
tulang akibat usia serta meningkatkan kesehatan secara umum, sehingga mengurangi resiko kejadian osteoporosis.

Kata kunci : Senam Osteoporosis, Osteoporosis, Peserta Senam

\section{PENDAHULUAN}

Osteoporosis

merupakan

kondisi atau penyakit dimana tulang menjadi rapuh dan mudah retak atau patah. Osteoporosis merupakan penyakit tulang degeratif yang ditandai oleh berkurangnya massa tulang, dan adanya kelainan mikroarsitektur jaringan tulang selama jangka waktu yang cukup lama. Bersamaan dengan penuaan, isi mineral tulang menurun secara lebih cepat pada wanita dari pada laki-laki, dan setelah menopause sampai $8 \%$ masa tulang hilang per dekade. Meskipun itu telah dipercaya efek dari penuaan dan perubahan hormonal, secara jelas dipercepat oleh kurangnya aktivitas fisik (inactivity) (Cosman, 2013).

Menurut

Departemen

kesehatan RI 2012, wanita memiliki resiko osteoporosis lebih tinggi yaitu $21,7 \%$, dibanding laki-laki yang hanya berisiko sebanyak $14,8 \%$, hal ini dikarenakan wanita mengalami proses kehamilan dan menyusui serta penurunan hormon estrogen pada saat pre menopause, menopause, dan pasca menopause. Selain itu, penelitian dilakukan pada 14 provinsi menunjukkan bahwa masalah osteoporosis telah mencapai pada tingkat yang perlu di waspadai yaitu $19,7 \%$. Itulah sebabnya angka osteoporosis di Indonesia 6 kali lebih besar daripada Belanda. Sedangkan penelitian yang dilakukan oleh Fitahul (2013) tentang hubungan kecemasan dengan tingkat kejadian osteoporosis di wonokromo, didapatkan lansia yang menderita osteoporosis sebanyak $(67 \%)$.
Dari hasil wawancara yang dilakukan peneliti kepada 10 orang peserta senam osteoporosis di Rumah Sakit Islam Surabaya, didapatkan sebanyak 7 orang mengatakan tidak ada keluhan sama sekali, 1 orang mengatakan kram kaki kiri pada malam hari, dan 2 orang lainnya mengatakan merasa nyeri di daerah punggung dengan intensitas nyeri hilang timbul dan tidak berlangsung lama. Sedangkan hasil wawancara yang dilakukan peneliti kepada 10 orang yang tidak aktif mengikuti senam didapatkan 8 orang mengatakan sering nyeri didaerah persendian, muda merasa lelah, dan kram pada malam hari, sedangkan 2 lainnya tidak ada keluhan.

Kejadian osteoporosis dapat di pengaruhi oleh beberapa faktor seperti, usia, jenis kelamin dan gaya hidup yang meliputi kebiasaan merokok, kurang konsumsi kalsium, kurang olahraga, minum-minuman bersoda, minum kopi, teh, susu dan alkohol. (Ferdinand, 2007). Kurang olahraga merupakan salah satu faktor penyebab osteoporosis, kurang berolahraga akan menghambat proses osteoblas pada tulang (proses pembentukan massa tulang), dan kepadatan massa tulang akan berkurang. Semakin banyak gerak dan olahraga maka otot akan memacu tulang untuk membentuk massa (Cosman, 2013). Tulang yang sudah tua dan pernah mengalami keretakan akan di bentuk kembali, tulang yang sudah rusak akan di identifikasi oleh sel osteosit (sel osteoblas menyatu dengan matriks tulang). Kemudian terjadi penyerapan kembali yang 
dilakukan oleh sel osteoklas dan nantinya akan menghancurkan kolagen yang mengeluarkan asam. Dengan demikian tulang yang sudah diserap oleh osteoblas yang berasal dari sel precursor yang berasal dari tulang belakang setelah sel osteoklas hilang (Cosman, 2013).

Peran dari petugas kesehatan dalam hal ini Dokter dan Perawat sangatlah dibutuhkan. Karena dengan adanya Perawat dan Dokter perannya akan membantu dalam mengatasi peningkatan angka prevalensi dari osteoporosis. Perawat sebagai pemberi asuhan keperawatan berperan dalam upaya pendidikan dengan memberikan penyuluhan tentang pengertian osteoporosis, penyebab, gejala osteoporosis dan pengelolaan osteoporosis dengan cara mengajarkan senam osteoporosis serta berperan dalam meningkatkan mutu, pemerataan pelayanan kesehatan peningkatan pengetahuan, sikap dan praktik pasien serta keluarganya dalam melaksanakan pengobatan osteoporosis. Hal ini akan memberi nilai posistif dalam upaya meningkatkan derajat kesehatan masyarakat (Afriwardi, 2010).

\section{METODE}

Penelitian ini menggunakan desain analitik pengukuran dan observasional, dengan pendekatan Cross sectional, populasi yaitu seluruh peserta senam osteoporosis yaitu sebesar 55 peserta dan sampelnya 48 peserta senam, tehnik sampling yang digunakan probability sampling, dengan metode pendekatan simple random sampling, Variabel independent atau variabel bebas dalam penelitian ini adalah senam osteoporosis sedangkan variabel dependent atau yang terikat adalah kejadian osteoporosis. Instrumenya menggunakan pemeriksaan kepadatan mineral tulang (BMD) dan Kuesioner. Uji nya menggunakan Spearman untuk menganalisis data dengan tingkat kemaknaan $\alpha=0,05$.

\section{HASIL \& PEMBAHASAN}

\section{a. Hasil}

Penelitian ini dilakukan di rumah sakit islam Surabaya, letaknya sangat strategis karena Rumah Sakit Islam Surabaya berada di Jalan Jendral Ahmad Yani 2-4. Kawasan ini ramai dan berada di kawasan yang padat penduduk. Muda terjangkau oleh alat transportasi apapun dikota Surabaya. Rumah sakit islam Surabaya di bangun di atas lahan seluas $8.607 \mathrm{~m}^{2}$, dengan lantai dasar sebesar $7.370 \mathrm{~m}^{2}$, lantai satu seluas $1.192 \mathrm{~m}^{2}$, halaman beserta taman seluas $560 \mathrm{~m}^{2}$, dan mempunyai parkir seluas $735 \mathrm{~m}^{2}$. hasil penelitina pada 48 responden didapatkan, hampir setengah $(43,8 \%)$ responden berusia 41-50 Tahun, hampir seluruhnya $(93,8 \%)$ berjenis kelamin perempuan, hampir setengah $(39,6 \%)$ berpendidikan tinggi, sebagian besar $(56,2 \%)$ pegawai swasta, sebagian besar $(68,8 \%)$ mempunyai kebiasaan minum susu tinggi kalsium, sebagian besar $(75 \%)$ mempunyai kebiasaan minum teh, sebagian besar $(60,4 \%)$ responden mempunyai kebiasaan minum kopi, hampir seluruhnya $(77,1 \%)$ tidak minum-minuman bersoda, hampir seluruhnya $(93,8 \%)$ tidak merokok, hampir seluruhnya $(79,2 \%)$ mengikuti senam osteoporosis.

Berdasarkan kejadian osteoporosis sebagian besar $(68,8 \%)$ responden menderita osteopenia.

\section{b. Pembahasan}


1. Senam Osteoporosis

senam yang rutin bisa mengurangi depresi melalui 2 cara. Pertama, senam mengeluarkan endorphin, zat perasaan baik yang berkaitan dengan suasana hati. Kedua interaksi dalam senam juga dapat mengurangi depresi, dari hasil penelitian sebagian besar $(63,2 \%)$ responden mengikuti senam osteoporosis sesuai kaidah, yaitu 1 kali dalam seminggu minimal 40 menit dalam sekali senam. Senam osteoporosis baik untuk segala usia. Faktor lain yang menmpengaruhi senam adalah pekerjaan, sebagian besar $(56,2 \%)$ bekerja sehingga waktu untuk melakukan senam osteoporosis sangat sedikit, tetapi pekerjaan yang dilakukan dengan cara mengangkat beban, bersepeda maupun berjalan kaki mempunyai manfaat yang sama dengan melakukan senam osteoporosis.

Berdiri tegap selama 40 menit akan mempunyai manfaat untuk perbaikan massa tulang, gabungan olahraga aerobik yang dilakukan dengan berdiri dan program penguatan otot umum akan mempunyai manfaat untuk meningkatkna kebugaran. Merekan yang tidak bisa melakukan dengan cara berdiri maka bisa melakukan dengan cara duduk ataupun berbaring, yang juga akan mempunyai manfaat untuk perbaikan massa tulang Cosman (2013).

\section{Osteoporosis}

Hasil penelitian didapatkan sebagian besar $(68,8 \%)$ responden menderita osteopenia, osteopenia merupakan suatu kondisi dimana kepadatan mineral tulang lebih rendah dari nilai DMT normal $(-1-2.5)$. Salah satu faktor yang mempengaruhi osteoporosis yaitu jenis kelamin. Berdasarkan tabel 5.2 menunjukkan bahwa hampir seluruhnya (93.8\%) responden berjenis kelamin perempuan, dimana perempuan lebih rentan terkena osteoporosis dibandingkan laki-laki. Perempuan mengalami menstruasi, dimana pada saat menstruasi hormon estrogen meningkat dan pembentukan osteoklas menurun, sehingga sangat baik untuk pembentukan massa tulang. Sedangkan pada saat menopaus kadar estrogen yang dimiliki tubuh sangat rendah sehingga sel osteoklas meningkat yang akan mengakibatkan resorpsi tulang lebih cepat dan kehilangan massa tulang lebih cepat. Menurut Cosman (2013) osteopenia pada perempuan merupakan hal yang wajar karena kepadatan tulang perempuan 5-10 kali lebih rendah dari pada laki-laki pada saat menopause. Faktor lain yang mepengaruhi osteoporosis adalah usia hampir setengah $(43.8 \%)$ peserta senam osteoporosis berusia 41-50 tahun. Pada usia ini banyak penyakit kronis yang frekuensinya mulai meningkat Cosman (2013). Pada usia 41-50 tahun banyak mengalami penerunan kemampuan baik kemampuan fisik maupun kemampuan intelektual dan juga pada usia ini sering mengeluh nyeri pada persendian dan tulang belakang, baik pada saat akitifitas maupun pada saat bangun tidur, dan pada saat duduk biasanya susah untuk berdiri lagi, hal ini di sebabkan penurunan drastis kadar estrogen pada saat menopaus dan penurunan kadar testosteron secara berangsur angsur saat andropaus yang mengakibatkan penurunan drastis massa tulang, dan juga bisa disebabkan kemampuan sel osteoblast yang mulai menurun untuk menutup lubang kecil pada tulang yang di sebabkan oleh osteoklast.

Faktor lain yang mepengaruhi kejadian osteoporosis adalah gaya 
hidup, dari hasil penelitian sebagian besar $(68,8 \%)$ responden minum susu tinggi kalsium, kalsium sangat dibutuhkan tubuh, oleh karena itu kita harus banyak mengkonsumsi makanan ataupun minuman yang mengandung kalsium, karena kalsium berperan penting dalam tubuh untuk membentuk tulang yang lebih kuat sehingga mengurangi terjadinya kropos tulang, Menurut Alexander (2014), sebagian besar kalsium dalam tubuh disimpan dalam tulang. Bahkan, tulang terdiri dari $40 \%$ kalsium. Ketika kadar kalsium dalam darah turun di bawah normal, kalsium di ambil dari tulang untuk mengembalikan kadar normal dalam darah. Tubuh kehilangan kalsium melalui urin, keringat dan tinja, dan karena terjadi secara langsung tanpa kita rasakan, anda harus cukup mengkonsumsi kalsium guna mempertahankna kadar normalnya dalam darah sehingga dapat mencegah tulang melepas cadangan kalsiumnya. Dengan demikian tulang dapat terlindungi dari pengeroposan.

Faktor selanjutnya yang dapat mempengaruhi kejadian osteoporosis adalah kebiasan mengkonsumsi minuman yang mengandung kafein, dari hasil penelitian sebagian besar $(75 \%)$ responden minum teh, dan sebagian besar $(60,4 \%)$ responden minum kopi, mengkonsumsi minuman yang mengandung kafein dapat berperan sebagai toksin dalam penyerapan kalsium oleh tubuh, sehingga kalsium lebih banyak dibuang melalui urin sebelum masuk kedalam tulang, dan pada saat kita mengkonsumsi kopi dan teh biasanya akan mengurangi dalam mengkonsumsi minuman yang mengandung kalsium, seperti minum susu. Menurut Alexander (2014), sedangkan dilihat dari kebiasaan responden minum-minuman bersoda hampir seluruhnya $(77,1)$ responden tidak minum-minuman bersoda. Walaupun soda yang mengandung fosfor di perlukan untuk perkembangan tulang normal, namun terlalu banyak fosfor dapat mengakibatkan kropos tulang Alexander (2014). Dan dari kebiasaan merokok hampir seluruhnya $(93,8 \%)$ responden tidak ada yang merokok. Menurut Alexander (2014) nikotin dalam rokok dapat menimbulkan masalah pada pembentukan tulang dengan cara mengganggu peran penting estrogen dan testosterone dalam perkembangan tulang.

3. Hubungan antara
osteoporosis
osteoporosis
dengan
Dari hasilian dapatkan $\rho=0.001$ yang berarti ada hubungan antara senam osteoporosis dengan kejadian osteoporosis, dan hasil crostabulation di dapatkan 10 orang yang senamnya tidak sesuai sebagian besar (60\%) mengalami osteopenia, hampir setengahnya (40\%) menderita osteoporosis dan tidak ada responden yang mempunyai massa tulang normal, sedangkan yang senamnya sesuai, minimal 1 kali dalam seminggu dengan jangka waktu minimal 40 menit, sebagian besar (71.1\%) mengalami osteopenia, hampir setengahnya (28.9\%) mempunyai massa tulang normal dan tidak ada yang menderita osteoporosis. Hal ini menunjukkan bahwa senam yang teratur dapat mempengaruhi massa tulang, sehingga dapat mengurangi resiko kejadian osteoporosis, senam ini akan merangsang tulang menjadi lebih kuat, tulang menjadi lebih padat dan lebih 
keras. Hal ini sesuai dengan teori Hans Tandra (2009) bahwa makin teratur dan rajin berolahraga, peredaran darah menjadi semakin baik dan nutrisi yang baik akan terus di alirkan ke tulang untuk keperluan pertumbuhan, pakailah tulang untuk berolahraga bila tidak ingin tulang menjadi keropos. Jadi, senam berguna agar tulang tidak banyak mengalami pengeroposan. Dari hasil penelitian dan teori diatas ada kesesuaian antara teori dan fakta dilapangan. Bahwa senam osteoporosis dapat mempengaruhi kejadian osteoporosis.

Senam yang dilakukan sesuai kaidah berguna untuk kesehatan tubuh dan juga bisa meningkatkan massa tulang sehingga bisa mengurangi resiko osteoporosis dan juga bisa mencegah terjadinya patah tulang pada saat terjatuh maupun kecelakaan. Menurut Zairin Noor (2014). Mengatakan bahwa senam yang dilakukan secara teratur akan membuat peredaraan darah menjadi semakin baik dan nutrisi yang baik akan terus dialirkan ke tulang untuk keperluan pertumbuhan yang berguna sebagai penguat otot, menambah kepadatan massa tulang mengurangi rasa nyeri dan menjaga kesehatan secara keseluruhan. Sedangkan orang yang tidak melakukan senam atau senamnya tidak sesuai kaidah dapat mempercepat penurunan massa tulang, karena osteoklas mengikis tulang secara terus menerus sedangkan osteoblas harus dirangsang dengan gerakan supaya bisa menutup tulang yang di buat oleh osteoklas, dan pada orang yang senamnya tidak sesuai akan memiliki faktor resiko osteoporosis yang lebih besar. Hal ini sesuai dengan teori Cosman (2013). Senam, baik bagi tulang maupun aspek kesehatan lain. Tidak bergerak sama sekali mempercepat penurunan massa tulang menyebabkan tulang menjadi kropos sehingga terjadi osteoporosis dan akan mengakibatkan tulang tersebut muda patah, sementara senam menahan beban tubuh bisa meningkatkan massa tulang, senam dapat memperlambat penurunan massa tulang akibat usia, serta meningkatkan kesehatan secara umum, sehingga mengurangi resiko terjatuh.

\section{SIMPULAN \\ Simpulan}

Berdasarkan hasil penelitian tentang hubungan senam osteoporosis dengan kejadian osteoporosis pada pesesta senam di Rumah Sakit Islam Surabaya dapat disimpulkan bahwa :

1. Peserta senam di Rumah Sakit Islam Surabaya hampir seluruhnya mengikuti senam osteoporosis.

2. Peserta senam di Rumah Sakit Islam Surabaya sebagian besar mengalami osteopenia.

3. Ada hubungan antara senam osteoporosis dengan kejadian osteoporosis pada peserta senam di Rumah Sakit Islam Surabaya.

\section{Saran}

1. Bagi peneliti

Sebagai tambahan ilmu pengetahuan dan pengalaman dalam dunia kesehatan dan dapat menerapkan senam sebagai cara yang tepat untuk membantu pasien dalam mengurangi atau bahkan mencegah terjadinya osteoporosis apabila dilakukan secara teratur.

2. Bagi profesi keperawatan

Diharapkan hasil penelitian ini dapat digunakan sebgai bahan pertimbangan dalam rangka meningkatkan mutu dan kualitas asuhan keperawatan yang dilakukan secara independent untuk membantu mengatasi masalah gangguan pada 
tulang khususnya yang berkaitan dengan pengeroposan massa tulang.

3. Bagi Universitas Nahdlatul Ulama Surabaya

Sebagai bahan referensi atau literatur bagi penelitian selanjutnya yang berkaitan dengan hubungan senam osteoporosis dengan kejadian osteoporosis dan sebagai bahan koleksi di perpustakaan Universitas Nahdlatul Ulama Surabaya.

4. Bagi peserta senam osteoporosis

Diharapkan lebih rutin mengikuti senam osteoporosis karena karena akan mengurangi resiko kejadian osteoporosis.

\section{DAFTAR PUSTAKA}

Afriwardi (2009). Ilmu kedokteran olahraga. Jakarta : EGC

Alexander dkk. (2011). Mengenal Osteoporosis Dan Osteopenia. Jakarta : Indeks

Arikunto, S (2006). Prosedur Penelitian Suatu Pendekatan Praktik. Jakarta : PT. Rineka Cipta. Budiman (2011). Penelitian Kesehatan. Bandung : Refika Aditama.

Compston (2011). Bimbingan Dokter Pada Osteoporosis. Jakarta : Dian Rakyat

Cosman (2009). Osteoporosis Panduan Lengkap Agar Tulang Anda Tetap Sehat. Yogyakarta : BFrist

Fitahul (2013). Hubungan Osteoporosis Dengan Kecemasan. Surabaya

Gomez (2011). Awas Pengeroposan Tulang. Jakarta : Arcan

Hidayat Aziz Alimul (2008). Metode Penelitian Keperawatan Terbaik dan Teknik Analisis Data. Jakarta : Salemba Medika.
Indriasari (2009). 100\% Sembuh Tanpa Dokter. Jogjakarta. Grahatama.

Juliet (2011). Bimbingan Dokter Pada Osteoporosis. Jakarta : Dian Rakyat

Lane, N (2006). Osteoporosis. Jakarta : Raja Grafindo Persada

Muhammad as'adi (2011). Jangan Abaikan Jalan Kaki!. Jogjakarta : DIVA press.

Menteri Pendidikan (2010). Peraturan perundang-undangan Th 2002. Jakarta : Salemba Medik

Noor (2014). Buku Ajar Osteoporosis. Jakarta : Salemba Medika

Notoatmodjo Soekidjo (2010). Metodologi Penelitian

Kesehatan. Jakarta : Rineka Cipta

Nursalam (2011). Konsep dan Penerapan Metodologi

Penelitian Ilmu Keperawatan: Pedoman Skripsi, Tesis, dan Instrument Penelitian Keperawatan Edisi 2. Jakarta : Salemba Medika

Proverawati (2013). Senam Kesehatan.Jakarta :EGC

Unusa (2014). Pedoman Penyusunan Penulisan Dan Prosedur Ujian Proposal Karya Tulis IlmiahSkripsi

Zaviera F (2010). Pencegahan Dini, Penanganan dan Terapi, Jogjakarta : Kata Hati 